\title{
Charts for the conservation of vernacular drystone retaining walls
}

\author{
H. H. Le ${ }^{1}$, J. C. Morel ${ }^{1}$, D. Garnier ${ }^{2}$ \& P. McCombie ${ }^{3}$ \\ ${ }^{I}$ Département Génie Civil et Bâtiment (CNRS, FRE3237), ENTPE, \\ France \\ ${ }^{2}$ Laboratoire des Matériaux et des Structures du Génie Civil \\ (CNRS, UMR113), ENPC, France \\ ${ }^{3}$ Department of Architecture and Civil Engineering, \\ University of Bath, UK
}

\begin{abstract}
Drystone walls are durable structures, due to their intrinsic ductility, permeability, and the strength of the materials used. Nevertheless, they can be subject to slow deterioration due to the weathering of the materials, application of loads for which they were not designed, impact, or inappropriate repair methods. It is then necessary to assess the condition of the structure, and design repairs or a replacement construction. A suitable design should then help to minimize the overestimation of the structure's resistance which will result in a waste of materials and resources. Actually, three methods may be used in the design of drystone retaining walls - the distinct element method, yield design and limit equilibrium analysis. Based on them, charts are suggested to facilitate initial design.
\end{abstract}

Keywords: drystone retaining walls, design charts, limit equilibrium, homogenization, yield design, UDEC.

\section{Introduction}

Substantial studies of drystone wall construction and performance have been carried out over the last 25 years, and these studies are ongoing, with the aim of guiding the maintenance, repair and new construction of these structures. In France and in the United Kingdom, drystone walls play an important role while representing a big part in the amount of road retaining walls (about one-sixth of 
road gravity retaining walls in France [1] and about half of highway retaining walls in Great Britain [2]). These structures have a long life: road dry-stone retaining walls in France and the UK were set up in the 19th and the early 20th centuries. However, the constituent materials are subject to weathering, especially to frost damage in colder climates, and so do deteriorate over long periods. Repair methods or even full reconstruction may be needed. In this case, engineers need a design method which allows economical construction by avoiding over-conservative design assumptions. Such methods need to be based upon a proper understanding of drystone retaining wall behaviour, which in some respects can differ from the behaviour of conventional mortared masonry or mass concrete gravity retaining structures. These methods can allow efficient use of materials and resources, to produce structures which are both sensitive to the local environment, and environmentally sustainable.

Three main methods have been used for modeling drystone retaining walls:

- Distinct element method (DEM)

- Yield design method (YDM)

- Limit equilibrium method (LEM)

These methods will be described. And design charts, which summarized the result of calculation using LEM, so as to facilitate initial design will also be presented.

\section{Distinct element method (DEM)}

This method was developed to analyse the deformation of jointed rock in rock mechanics (Cundall [4]). The principle of DEM is to set up and to solve the equation of motion for the elements. For each time step, a force-displacement law is used to determine the contact forces, whilst Newton's second law defines the instantaneous acceleration of the contact, which is integrated to give the velocity. Once the relative velocity between the contact points is known, the relative displacements must be calculated and new contact forces are set up. This cycle is repeated until the dynamic equilibrium is achieved.

Based on the theory of DEM, a program was created named UDEC (Universal Distinct Element Code) (Itasca [3]). In the field of drystone construction, it was used by Walker and Dickens to simulate the behaviour of the free-standing and retaining walls of Great Zimbabwe [5]. It was also applied by Harkness et al. [6] and by Claxton et al. [7] to model the well-known four drystone wall tests by Burgoyne [8] and it showed an agreement with the experimental results as well as the limit equilibrium analysis.

The stone, the soil and the bedrock are all considered as elastic/MohrCoulomb plastic materials. The cross sections of the wall, the backfill and the rock foundation are divided into meshes of discrete elements (fig.1). Wall blocks are defined as rigid whereas the backfill soil is treated as deformable. The greater number of elements, the greater the possible precision of the result, but the more time was required for the calculation, and given uncertainties in the input data the value of such precision is very questionable. It took Harkness et al. about 7 days using an RS6000 workstation to carry out the calculation on a mesh of 
6427 elements in 2D, but developments in the use of the software by Claxton et al. cut the time for a run down to 60-80 minutes whilst still achieving realistic results, and developments in computer hardware since then have reduced computation time considerably further.

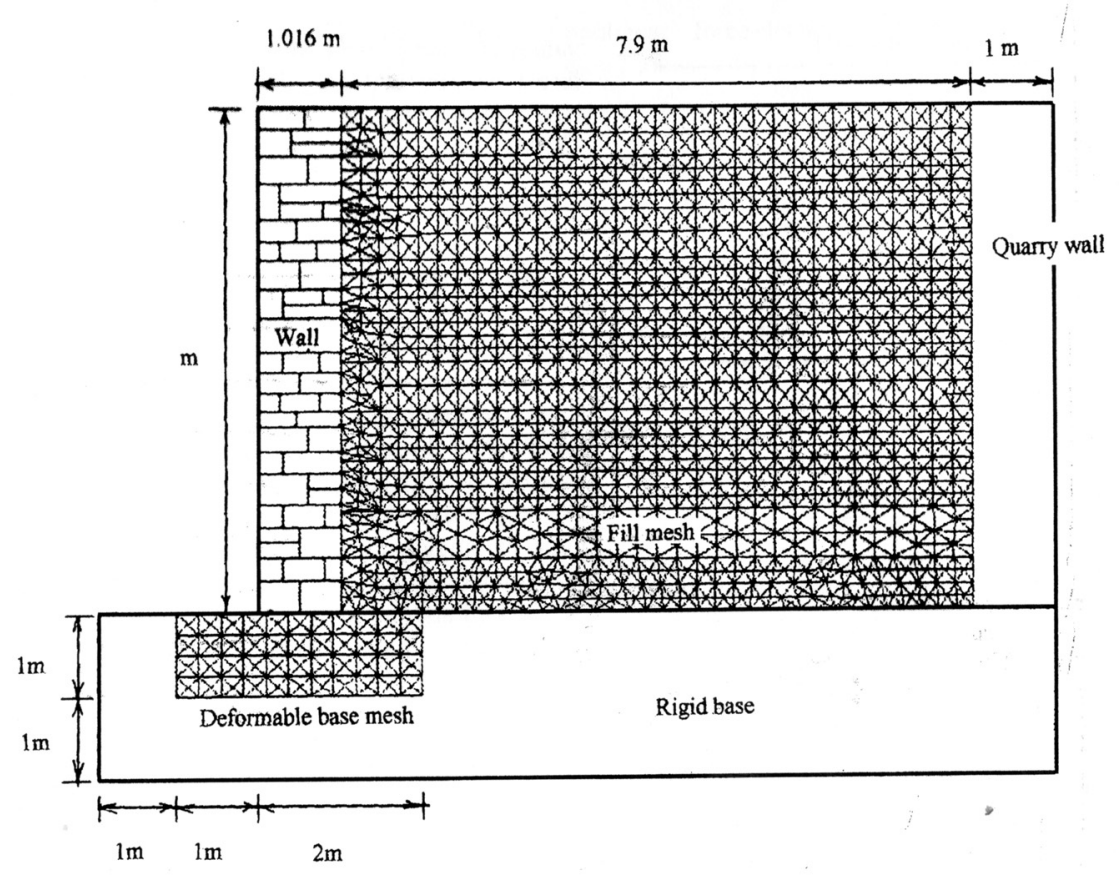

Figure 1: Distinct element model by Claxton et al. 2005.

The method is useful for exploring aspects of drystone behaviour, and for investigating the sensitivity to variations of the input parameters and the geometry, but given the difficulty of ascertaining the exact geometry in three dimensions, so is not useable for routine design and assessment of drystone retaining structures.

\section{Yield design method (YDM)}

This method of designing the drystone retaining walls is proposed by Colas et al. [9]. In general, the calculation is realized in 2 main steps:

- Step 1: The wall is supposed to be built from regular cut stone blocks so that it could be considered as periodic. It is then homogenized using the theory of homogenization for periodic masonry developed by de Buhan and de Felice [10].

- Step 2: The yield design theory gives the equations relating the different parameters of geometry, loading mode and resistance of the material. The failure 


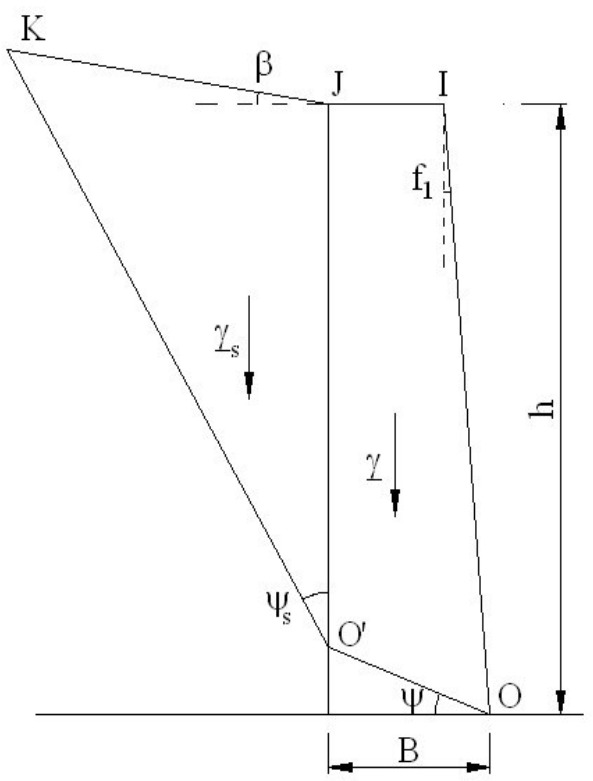

Figure 2: $\quad$ Yield design model by Colas 2008.

is assessed in two separate cases: by sliding and overturning. Note that in both cases, the friction angle at the soil-wall interface was assumed to be equal to the internal friction angle of the soil.

In her calculation, Colas considered a backfill height different from the height of the wall and evaluated the wall stability in relation to the soil height that the wall could support. However, in a design problem, the backfill will generally extend to the top of the wall, and the base width is the unknown parameter which needs to be determined.

Though the yield design is more complicated than the limit equilibrium, it might be supposed to give better results because the angle $\psi$ between the horizontal and the failure line was not supposed but calculated. Moreover, it is hopeful that this model will be developed in 3D, which is being studied now at ENTPE (Ecole Nationale des Travaux Publics de l'Etat), France.

\section{Limit equilibrium method (LEM)}

This method is usually applied to the design of gravity retaining walls. The use of it for drystone retaining walls was studied by Villemus et al. [11] and then Mundell et al. [12]. Villemus developed his calculations considering that the wall was monolithic, whereas Mundell presented a computer program which treated the wall as a series of stacked layers. 


\subsection{Monolithic wall analysis}

The calculation model used by Villemus is as in figure 3. Two modes of failure were considered, sliding and overturning. In both cases, the structure is separated into two monoliths by a plane an angle $\psi$ to the horizontal. The value of $\psi$ is determined by consideration of the physical characteristics of the structure being analysed. For failure by sliding, the recommended values are 0 if the wall is built from cut stone and 0.2 radian $\left(11.5^{\circ}\right)$ for rough stone. Villemus did not give a specific value for $\psi$ for overturning, but suggested that it should lie between 0 and 0.2 radian - the limit given by the slenderness of blocks. Considering that a drystone retaining wall is not a rigid solid and that local block rotation may occur, $\psi=0.2$ radian is suggested. The minimal base thickness required which assures the wall stability is determined by equilibrating the resisting and unstable actions (forces or moments). The more dangerous case is the one which gives the minimal base thickness required more important. It will decide the ultimate base thickness.

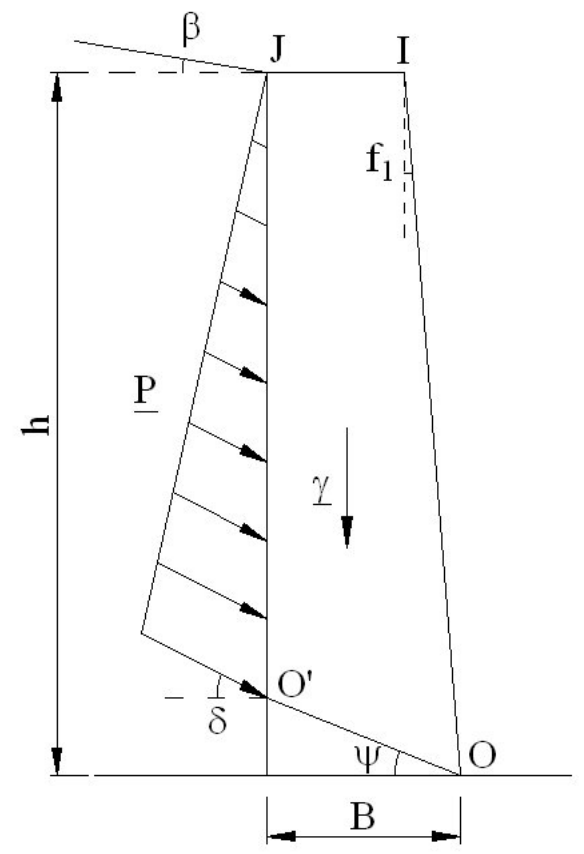

Figure 3: Limit equilibrium model of monolithic wall.

The analysis requires a value for the friction angle at the wall/backfill interface $(\delta)$, which was not considered by Villemus in his analysis of hydraulically loaded experimental structures, which could not apply any friction on the internal face of the wall. However, in the general case of earth backfill, based on the work of Colas et al. [9], $\delta$ may be set equal to $\varphi_{\mathrm{s}}$, the backfill friction angle. 


\subsection{Multi-block wall analysis}

Mundell developed a program using the Delphi development environment to analyze the stability of walls. This program was created for the purpose to replace hand calculation without resorting to the complexity of numerical modelling such as using UDEC (Universal Distinct Element Code). The wall is considered to be composed of series of stacked blocks with horizontal upper and lower surfaces, and each block extending from the front to the back of the wall and representing a complete course of stone within the real structure. The geometry and position of these blocks thus determines the overall geometry of the wall. The program allows this geometry to be altered by a mouse-click on the cross-section shown on the computer monitor, or by entering new values into the table of data. The new positions of the resultant forces at each block interface are shown virtually instantaneously, together with the 'line of thrust' (see, for example, Cooper [13], Heyman [14]). Provided that the line of thrust lies within the structure, then overturning will not occur. The program also analyses sliding stability.

Each of the $n$ blocks is identified by the co-ordinates of its 4 vertices (figure 4), and its area and centroid are determined.

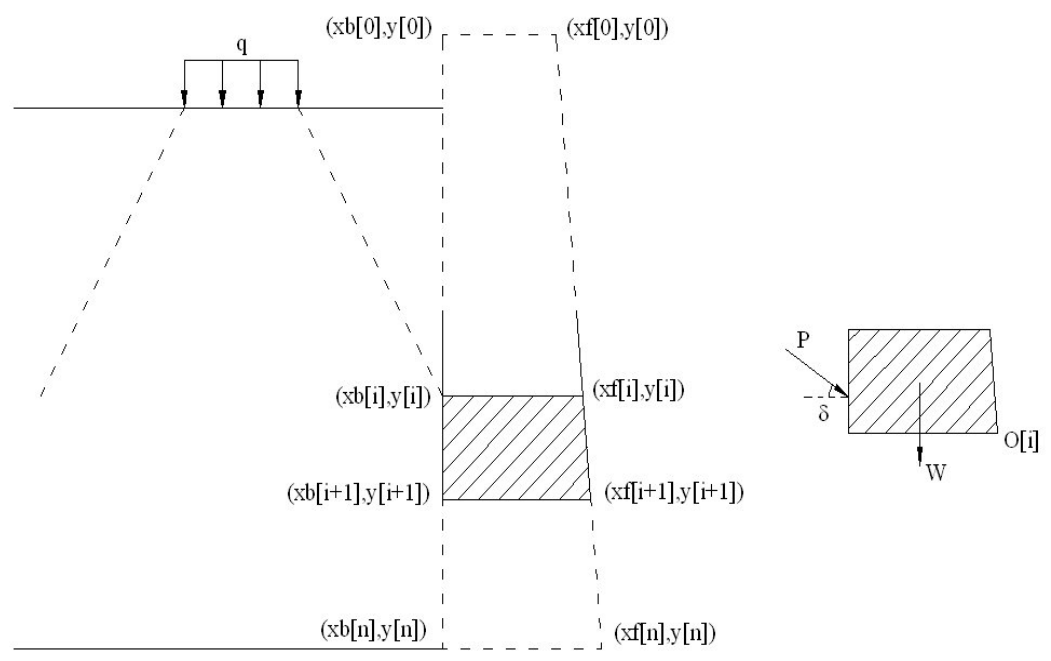

Figure 4: $\quad$ Limit equilibrium model of multi-block analysis.

The applied loads to each block are composed of:

- block weight $(W)$ : It is calculated by multiplying the area and the unit weight of the material. It takes the centroid of the block as its point of application.

- backfill pressure $(P)$ : is represented by a force acting at an angle of $\delta$ with the normal of the internal face, placed at a height determined by the difference in pressure between the top and bottom of the block. 
- $\quad$ surcharge $(q)$ : The influence of a surcharge applied to a limited area of the ground behind the top of the wall is determined by assuming that the load spreads out over an area which increases with depth by a ratio of ( 1 horizontal : 2 vertical) in all directions, but limited by the position of the back of the wall. The surcharge application is only taken into consideration when this load spread touches the wall.

Load transmitted from the block above (zero for the topmost block). The calculation begins from the block at the top and continues to the lowest one. To evaluate the wall stability, the program checks three possible failure modes: overturning, sliding and block rotation (Claxton et al. [7]). The wall is no longer stable when the sliding or overturning forces overpass the resisting ones.

\section{Design charts of drystone retaining walls}

Design charts based on the limit equilibrium theory for the monolithic wall are found in a Design Guide published in 2008 by ENTPE [15]. This guide was prepared in cooperation with the masons specialized in drystone walling. Walls must be built through their expertise that ensures compliance with the building code and engineering assumption of the monolithic behaviour of the walls in 2D. Such behaviour was verified by experiments (Villemus et al. [11], Colas et al. [9]). On the other hand, the safety factors usually used on gravity retaining walls in France were applied. Finally the assumption of friction $\delta=\varphi_{\mathrm{s}}$ was applied to the contact between the backfill and the wall (as Mundell et al. [12] and Colas et al. $[9,16-18] \mathrm{did})$.

The guide provides 18 charts in total, corresponding to 2 kinds of stone, 3 values of backfill slope $(\beta)$ and 3 different values of external batter of wall face $\left(f_{1}\right)$ as follow:

- Materials : limestone, schist

- Backfill slope: $0^{\circ}, 10^{\circ}, 20^{\circ}$

- External batter: $0 \%, 10 \%, 20 \%$

An example of a chart design given in the Design Guide is shown in figure 5. That is the case of walls in schist with the external batter of $10 \%$ and a backfill slope of $10^{\circ}$. The $\mathrm{X}$-axis represents the backfill friction angle $\left(\varphi_{s}\right)$ measured in degrees while the Y-axis represents the base thickness of the wall $(B)$ measured in meters. 10 curves are given corresponding to 10 different wall heights varying from $0.5 \mathrm{~m}$ to $6 \mathrm{~m}$. Therefore, once knowing $\varphi_{s}$, the engineer can preset the wall height $(h)$ and then consult the chart to find the base thickness of the wall. This is the minimal value that should be respected to assure that the wall is stable. For example, in the case the $2.5 \mathrm{~m}$ high schist wall should retain a backfill whose friction angle is $30^{\circ}$, the minimal base thickness required so that the wall remains stable is $1.4 \mathrm{~m}$. The thickness at the coping could also be calculated if necessary, based on the 3 parameters: $h, f_{l}$ and $B$. In this example, it is $1.15 \mathrm{~m}$.

It should be noted that here only the walls whose the internal face is vertical $\left(f_{2}=0\right)$ and the courses are horizontal are considered. For the other cases of $\beta$ and 


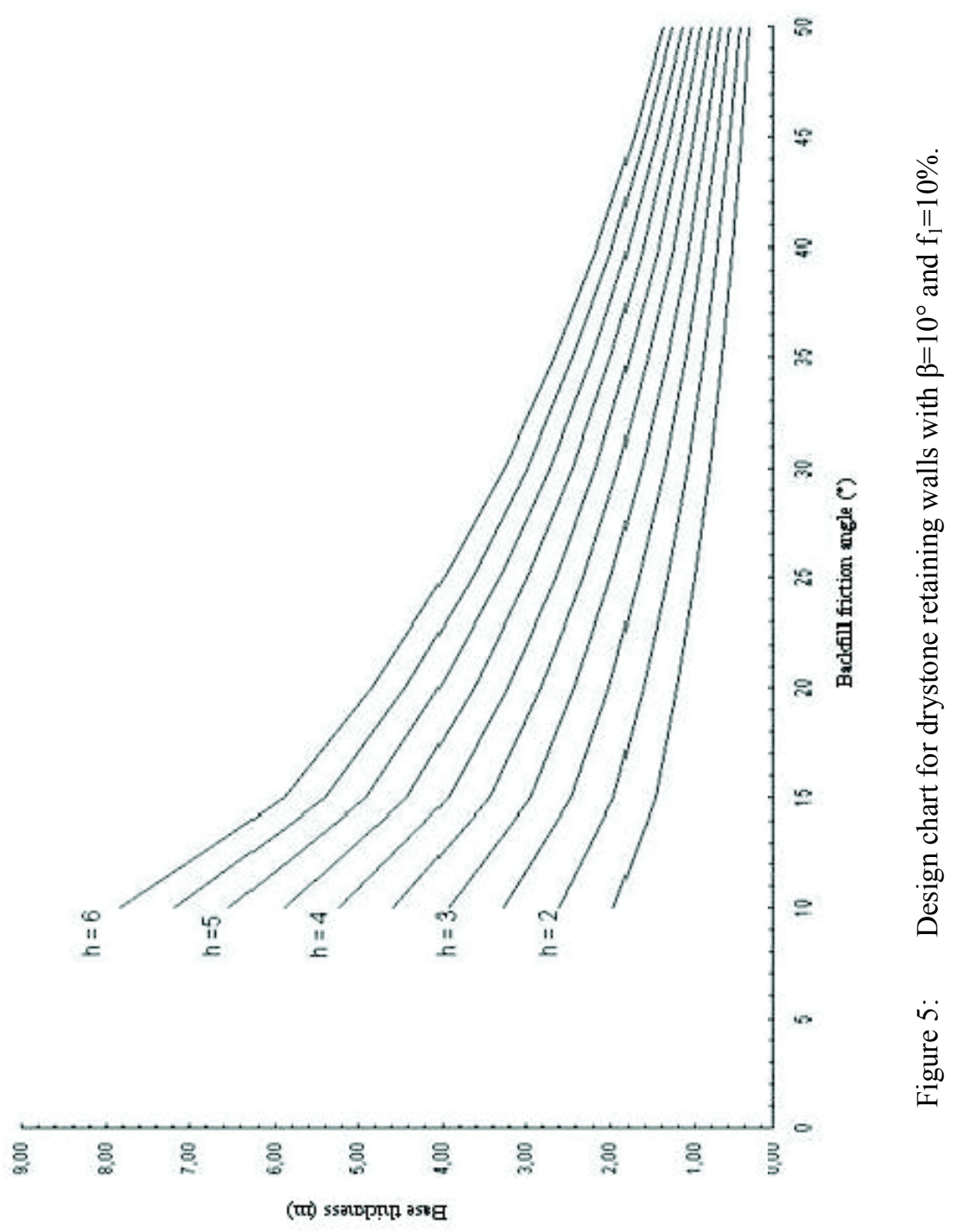


$f_{l}$ which can't be found in the list above, there are two ways to solve them: we could either use the method of linear interpolation or simply take the most proximate value of the reference parameters.

\section{Conclusion}

The design is the first step in the construction of all structures. A good design method helps much in economizing the cost of the construction as well as the engineers' precious time. In comparison with the numerical design methods for drystone retaining walls, the simplified methods presented above are less advantageous in simulating the behavior of the wall. On the contrast, they are simpler, faster and more practical, in particular when evaluating the wall stability. Moreover, the designer does not depend on the computer to do his work. The design charts, which summarize the results of stability calculation of drystone walls, are not only useful but also easy to use. Thanks to them, we could quickly anticipate the geometry of the wall.

\section{Nomenclature:}

$\beta$ - backfill slope (radian)

$\delta$ - friction angle at the wall/backfill interface (radian)

$\gamma$ - density of the wall $\left(\mathrm{kN} / \mathrm{m}^{3}\right)$

$\gamma_{\mathrm{s}}-$ density of the soil $\left(\mathrm{kN} / \mathrm{m}^{3}\right)$

$\psi$ - angle between the horizontal and the plan of failure of the wall (radian)

$\psi_{\mathrm{s}}$ - angle between the internal face of the wall and the plan of failure of the backfill (radian)

$\varphi$ - internal friction angle of the wall (radian)

$\varphi_{\mathrm{s}}-$ internal friction angle of the soil (radian)

$\mathrm{P}$ - backfill pressure $\left(\mathrm{kN} / \mathrm{m}^{2}\right)$

$\mathrm{q}$ - surcharge $\left(\mathrm{kN} / \mathrm{m}^{2}\right)$

$\mathrm{V}$ - vertical component of the resultant of external forces $(\mathrm{kN})$

$\mathrm{W}$ - block weight $(\mathrm{kN})$

\section{Acknowledgements}

This work is part of the national project PEDRA (Weakly bonded and drystone structures) - program C2D2 10 MGC S 01 - financially supported by the Ministry of Ecology and the Network of Civil and Urban Engineering (RGCU). The authors would like to acknowledge these institutions for their support.

\section{References}

[1] Odent, N., Recensement des ouvrages de soutènement en bordure du réseau routier national, Ouvrage d'Art, 34, pp. 15-18, 2000.

[2] O'Reilly, M.P., Bush, D.I., Brady, K.C. \& Powrie, W., The stability of drystone retaining walls on highways, Proceedings of the Institution of Civil Engineers, 133(2), pp. 101-107, 1999. 
[3] Itasca Consulting Group, UDEC Version 3.0 User Manual, Minnesota, 1996.

[4] Cundall, P.A., A computer model for simulating progressive large scale movements in blocky rock systems. Proceedings of the Symposium of the International Society for Rock Mechanics, Paper No. II-8, Nancy, 1971.

[5] Walker, P.J. \& Dickens, J.G., Stability of medieval dry stone walls in Zimbabwe, Géotechnique, 45(1), pp. 141-147, 1995.

[6] Harkness, R.M., Powie, W., Zhang, X., Brady, K.C. \& O’Reilly, M.P., Numerical modeling of full-scale tests on drystone masonry retaining walls, Géotechnique, 50(2), pp. 165-179, 2000.

[7] Claxton, M., Hart, R. A., McCombie, P. F. \& Walker, P., Rigid block distinct element modeling of dry-stone retaining walls in plane-strain. Journal of Geotechnical and Geoenvironmental Engineering, 131 (3), pp. 381-389, 2005.

[8] Burgoyne, J. Revetment of retaining walls, Corps of Royal Engineering, Papers 3, pp. 154-159, 1853.

[9] Colas, A.S., Morel, J.C. \& Garnier, D., Yield design of dry-stone masonry retaining structures - Comparisons with analytical, numerical and experimental data, International journal for numerical and analytical methods in geomechanics, 32, pp. 1817-1832, 2008.

[10] de Buhan, P. \& de Felice, G., A homogenization approach to the ultimate strength of brick masonry, Journal of the Mechanics and Physics of Solids, 47(7), pp. 1085-1104, 1997.

[11] Villemus, B., Morel, J.C. \& Boutin, C., Experimental assessment of dry stone retaining wall stability on a rigid foundation, Engineering Structures, 29(9), pp. 2124-2132, 2007.

[12] Mundell, C., McCombie, P., Bailey, C., Heath, A. \& Walker, P., Limit equilibrium assessment of drystone retaining structures, Geotechnical Engineering, 162 (GE4), pp. 203-212 (10.1680/geng.2009.162.4.203), 2009.

[13] Cooper, M.R., Deflections and failure modes in drystone retaining walls, Ground Engineering, 19(8), pp. 28-33, 1986.

[14] Heyman, J., Poleni's problem (Part 1), Proc. Instn. Civ. Engrs, 84, Aug., pp. 737-759, 1988.

[15] CAPEB, Guide des bonnes pratiques de construction de murs de soutènement en pierre sèche, Paris, 2008.

[16] Colas, A.S., Morel, J.C \& Garnier, D., Full-scale field trials to assess drystone retaining wall stability, Engineering Structure, 32(5), pp.1215-1222, 2010.

[17] Colas, AS., Morel, J.C. \& Garnier, D., 2D modelling of a dry joint masonry wall retaining a pulverulent backfill, Int. J. Numer. Anal. Meth. Geomech., (34), pp.1237-1249, 2010.

[18] Colas, A.S., Morel, J.C. \& Garnier, D., Yield design modelling of dry-stone retaining walls, Structural Studies, Repairs and Maintenance of Heritage Architecture, pp. 449-457, STREMAH, Prague, July 2007. 